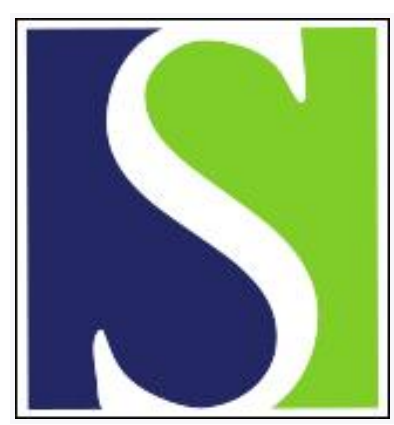

Scand J Work Environ Health 2006;32(5):383-391

https://doi.org/10.5271/sjweh.1034

Issue date: 31 Oct 2006

Acute response of finger circulation to force and vibration applied to the palm of the hand

by Griffin MJ, Welsh AJL, Bovenzi M

Affiliation: Human Factors Research Unit, Institute of Sound and Vibration Research, University of Southampton, Southampton, S017 1BJ, United Kingdom. M.J.Griffin@soton.ac.uk

Refers to the following texts of the Journal: 1998;24(2):130-137 1999;25(3):278-284

Key terms: acute response; finger blood flow; finger circulation; force; hand palm; hand-transmitted vibration; palm of the hand; vibration

This article in PubMed: www.ncbi.nlm.nih.gov/pubmed/17091206

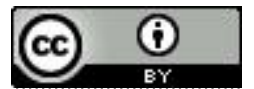




\title{
Acute response of finger circulation to force and vibration applied to the palm of the hand
}

\author{
by Michael J Griffin, PhD, ${ }^{1}$ Alexandra JL Welsh, BSc, ${ }^{1}$ Massimo Bovenzi, MD ${ }^{2}$
}

\begin{abstract}
Griffin MJ, Welsh AJL, Bovenzi M. Acute response of finger circulation to force and vibration applied to the palm of the hand. Scand J Work Environ Health 2006;32(5):383-391.

Objectives This study investigated the effects of force at the palm on acute changes in finger circulation during exposure to vibration.

Methods Ten persons attended five sessions consisting of the following five successive 5-minute periods: (i) no force and no vibration, (ii) force and no vibration, (iii) force and vibration, (iv) force and no vibration, and (v) no force and no vibration. During the second and fourth periods, the palm of the right hand applied $5 \mathrm{~N}$ or $20 \mathrm{~N}$ to a platform that vibrated $\left(125 \mathrm{~Hz}, 64 \mathrm{~m} / \mathrm{s}^{2}\right.$ root mean square) during the third period. Finger blood flow was measured in the middle and little fingers of the right (exposed) hand and the middle finger of the left (unexposed) hand.

Results A force of $20 \mathrm{~N}$ alone reduced the mean finger blood flow in the ipsilateral and contralateral fingers. Finger blood flow was also reduced by vibration, with greater reductions when vibration was combined with 20 $\mathrm{N}$ of force. Vibration caused vasoconstriction in the fingers of both the vibrated and nonvibrated hands.

Conclusions Force applied to the palm reduced blood flow in the fingers of the exposed hand, probably due to compression of the vascular system supplying the fingers. There was evidence that force may reduce finger blood flow in the contralateral hand, possibly due to a central sympathetic effect. Vibration at $125 \mathrm{~Hz}$ applied to the palm of the hand reduced finger blood flow in fingers of that hand and also in a finger of the contralateral hand. In this study, any local effects of vibration were less than those of central sympathetic origin.
\end{abstract}

Key terms finger blood flow; force; hand palm; hand-transmitted vibration.

Occupational exposures of the hand to the vibration of many types of handheld power tools are responsible for various disorders collectively known as the hand-arm vibration syndrome $(1,2)$. One component of the syndrome is a vascular disorder known as vibration-induced white finger in which there is complete episodic closure of digital blood vessels resulting in attacks of well-demarcated finger blanching (3). The attacks of blanching are most commonly provoked by cold, but the physical conditions causing the underlying disorder are not well established (4).

Current standards define uniform methods of measuring and evaluating exposures to hand-transmitted vibration so as to quantify daily doses of vibration, and regulations define limiting exposures $(5,6)$. Nevertheless, the current methods of assessing the risks of disorder are only loosely based on scientific data (7). In the standards, it is currently assumed that the risks can be predicted solely from the magnitude and the frequency of the vibration and the duration of the exposure. It seems likely that other factors have an influence, including the location of contact with vibration and the pressure of the contact with the fingers or hand (5).

Epidemiologic studies have investigated the relationships between some measures of vibration exposure and the probability of disorder (8) but have had limited power to investigate the effects of the frequency, magnitude, and duration of exposure to vibration and some of the other factors that may influence the risk of injury. Laboratory studies allow the systematic investigation of

Human Factors Research Unit, Institute of Sound and Vibration Research, University of Southampton, Southampton, United Kingdom.

2 Clinical Unit of Occupational Medicine, Department of Public Health Sciences, Trieste General Hospitals, University of Trieste, Trieste, Italy.

Reprint requests to: Professor MJ Griffin, Human Factors Research Unit, Institute of Sound and Vibration Research, University of Southampton, Southampton, SO17 1BJ, United Kingdom. [E-mail: M.J.Griffin@soton.ac.uk] 
variables but cannot reproduce the conditions causing the chronic disorder-due to ethical considerations and the months or years of exposure required to produce the disease.

We have previously reported acute changes in finger blood flow produced by laboratory exposures of fingers to vibration and systematically explored how reductions in the flow depend on the frequency, magnitude, and duration of exposure (9-12). We have also reported the effects of various combinations of finger push force (no force, $2 \mathrm{~N}$ or $5 \mathrm{~N}$ ) and vibration $[31.5 \mathrm{~Hz}$ at 4 and $16 \mathrm{~m} / \mathrm{s}^{2}$ root mean square (rms) and $125 \mathrm{~Hz}$ at 16 and $64 \mathrm{~m} / \mathrm{s}^{2} \mathrm{rms}$ ] on finger blood flow in an exposed right middle finger, an unexposed right little finger, and an unexposed left middle finger (13). Force alone reduced finger blood flow in the exposed finger but not in the other fingers. In the vibrated finger and the nonvibrated fingers, there were additional reductions in finger blood flow caused by vibration with greater reductions at the higher vibration magnitudes at both frequencies. It appears that modest levels of force applied by a finger can have a large effect on finger blood flow in that finger, but the force applied by a finger did not cause changes in finger blood flow in other fingers. A recent study has found that a $2-\mathrm{N}$ push force applied to the medial phalanx of a finger reduced blood flow in the exposed finger (14).

When some power vibratory tools (eg, some etching tools) are operated, there may be direct contact between the body and the vibration only at the fingers, but most power tools require a palm grip where vibration enters the hand and fingers over a large area. The finding of the previous study of the effects of force on a finger may be explained by pressure on tissues causing constriction of local blood vessels. Such an effect would differ if the force were applied to the hand or fingers at other locations.

Pressure can be expected to compress the tissues of the body and reduce blood flow local to the application of pressure or reduce blood flow to distal locations if the force obstructs arterial supply. The greater effect with greater force may arise from more constriction or from larger areas being constricted. The compression of tissues may also alter the dynamic response of the tissues, changing the way vibration is transmitted to the finger or hand (13). This change could result in an interaction between the effects of force and vibration. For example, vibration may have a greater effect when there is a higher magnitude of force.

The objective of our present study was to extend previous findings of the effects of vibration on the finger by determining whether vibration applied to the palm of the hand reduced finger blood flow and whether any reduction in blood flow caused by vibration was influenced by variations in the force applied to the palm.

\section{Study population and methods}

\section{Study population}

Ten healthy male volunteers, seven Caucasian and three Asian, gave their written informed consent to participate in the investigation. All of the participants were students or office workers with no history of regular use of handheld vibrating tools in occupational or leisuretime activities. Eight were nonsmokers. None reported cardiovascular or neurological disorders, connective tissue diseases, injuries to the upper extremities, a history of cold hands, or use of medication. The mean age of the participants was 27.4 (SD 6.5, range 19-40) years, their mean stature was 179 (SD 8.0, range 165-187) cm, and their mean weight was 77 (SD 8.0, range 64-86) $\mathrm{kg}$. Finger dimensions were measured with vernier callipers. Finger volume was calculated from that of a cylinder formed from an ellipse based on the dimensions (length, breadth and depth) of the proximal, medial, and distal phalanges. The mean volume of the middle right finger was 23.9 (SD 3.0) $\mathrm{cm}^{3}$, that of the little right finger was 12.2 (SD 1.0) $\mathrm{cm}^{3}$, and that of the middle left finger was $22.9(\mathrm{SD} 2.4) \mathrm{cm}^{3}$.

\section{Measures of finger circulation}

Finger blood flow was measured in the middle fingers of both hands and in the little right finger. Mercury-insilastic strain gauges were placed around the distal phalanx at the base of the nails, and plastic pressure cuffs for air inflation $(9.5 \times 2.5 \mathrm{~cm})$ were fixed around the proximal phalanges and secured with a velcro strip. Three pressure cuffs and strain gauges were connected to a multichannel plethysmograph (HVLab, Institute of Sound and Vibration Research, University of Southampton, Southampton, UK).

The finger blood flow was measured using a venous occlusion technique. The pressure cuffs were inflated to a pressure of $60 \mathrm{mmHg}$, and the increases in finger volumes were detected by means of strain gauges according to the criteria given by Greenfield et al (15). The finger blood flow measurements were expressed in milliliters per $100 \mathrm{ml}$ per second.

Brachial systolic and diastolic blood pressures were measured in the upper right arm by an ausculatatory technique with the participants supine.

Room temperatures were measured using a thermocouple located adjacent to the participants' heads.

\section{Experimental procedure}

The experiment was performed in a laboratory room with a mean temperature of $25.8(\mathrm{SD} 0.8)^{\circ} \mathrm{C}$. The participants were requested to avoid caffeine, tobacco, and alcohol consumption for 2 hours prior to the testing. 


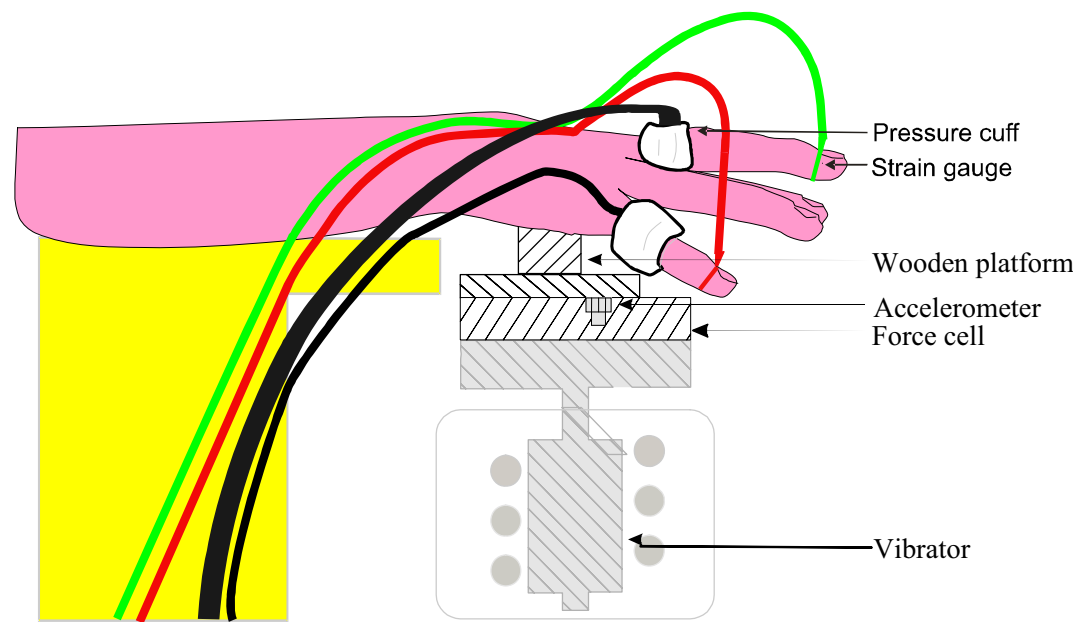

Figure 1. Experimental set-up used for generating vibration, controlling the contact force and measuring finger blood flow.
Each of the 10 participants attended five sessions in the laboratory. In each session, they experienced the following five successive experimental periods of 5 minutes: (i) no force and no vibration, (ii) force and no vibration, (iii) force and vibration, (iv) force and no vibration, and (v) no force and no vibration.

Throughout each session, the participants lay supine with their hands resting on platforms alongside their body at the level of the heart. After a period of acclimatization of about 20 minutes, finger blood flow was measured in the middle right and left fingers and the little right finger at 1-minute intervals during the $5 \mathrm{~min}$ utes of the first period. The right hand was then moved by the experimenter so that the center of the palm was positioned on a cylindrical wooden platform with a domed end. The diameter of the circular contact was 25 $\mathrm{mm}$, the radius of curvature of the dome being $25 \mathrm{~mm}$. During the second period the participants were asked to apply a downward force of either 5 or $20 \mathrm{~N}$ with the palm on the platform that was mounted on an electrodynamic vibrator (VP4, Derritron, Hastings, UK). The signal from a force cell (Tedea Huntleigh, Cardiff, UK) mounted between the platform and the vibrator was used to provide visual feedback on a meter for the control of downward force. All of the fingers of the right hand were suspended in air (figure 1). The left hand remained supported at heart height to the left of the body.

During the third period, sinusoidal vertical vibration was presented for 5 minutes, followed by a period with force without vibration during the fourth period. The right hand was then moved by the experimenter so that it was again supported on a platform at heart height alongside the participant for the fifth period.

The vibration during the third period had an acceleration magnitude of $64 \mathrm{~m} / \mathrm{s}^{2} \mathrm{rms}$ unweighted $\left(8.0 \mathrm{~m} / \mathrm{s}^{2} \mathrm{rms}\right.$ weighted) at $125 \mathrm{~Hz}$. There were, in addition, two conditions with force $(5$ or $20 \mathrm{~N}$ ) but no vibration and one
Table 1. Experimental design of the study-condition of exposures to push force alone (newtons) and the combinations of push force and $125-\mathrm{Hz}$ vibration with an acceleration magnitude of $64 \mathrm{~m} / \mathrm{s}^{2}$ root mean square. Condition $A$ was the control condition. $(\mathrm{min}=$ minutes $)$

\begin{tabular}{|c|c|c|c|c|c|c|c|}
\hline \multirow{4}{*}{$\begin{array}{l}\text { Condi- } \\
\text { tion }\end{array}$} & \multicolumn{7}{|c|}{ Exposure period (time interval) } \\
\hline & \multirow{3}{*}{$\begin{array}{c}\begin{array}{c}\text { First } \\
(1- \\
5 \mathrm{~min})\end{array} \\
\begin{array}{c}\text { Force } \\
(\mathrm{N})\end{array}\end{array}$} & \multirow{3}{*}{$\begin{array}{c}\begin{array}{c}\text { Second } \\
(5-\end{array} \\
10 \mathrm{~min}) \\
\begin{array}{c}\text { Force } \\
(\mathrm{N})\end{array}\end{array}$} & \multicolumn{3}{|c|}{$\begin{array}{c}\text { Third } \\
\text { (10-15 min) }\end{array}$} & \multirow{3}{*}{$\begin{array}{c}\begin{array}{c}\text { Fourth } \\
(15- \\
20 \mathrm{~min})\end{array} \\
\begin{array}{c}\text { Force } \\
(\mathrm{N})\end{array}\end{array}$} & \multirow{3}{*}{$\begin{array}{c}\begin{array}{c}\text { Fifth } \\
(20- \\
25 \text { min }\end{array} \\
25 \\
\begin{array}{c}\text { Force } \\
\text { (N) }\end{array}\end{array}$} \\
\hline & & & \multirow{2}{*}{$\begin{array}{l}\text { Force } \\
\text { (N) }\end{array}$} & \multicolumn{2}{|c|}{ Vibration } & & \\
\hline & & & & $\mathrm{Hz}$ & $\mathrm{m} / \mathrm{s}^{2}$ & & \\
\hline$A$ & - & - & - & - & - & - & - \\
\hline B & - & 5 & 5 & - & - & 5 & - \\
\hline C & - & 20 & 20 & - & - & 20 & - \\
\hline D & - & 5 & 5 & 125 & 64 & 5 & - \\
\hline$E$ & - & 20 & 20 & 125 & 64 & 20 & - \\
\hline
\end{tabular}

condition with no force and no vibration, giving a total of five conditions (table 1).

For the 5-minute duration of vibration exposure, the 8 -hour energy-equivalent frequency-weighted acceleration magnitude [ie, $A(8)]$ was $0.816 \mathrm{~m} / \mathrm{s}^{2} \mathrm{rms}$ in conditions $\mathrm{D}$ and $\mathrm{E}$ according to international standard 5349$1(5)$.

Finger blood flow was measured at 1-minute intervals in the middle and little right (exposed) fingers and in the middle left (unexposed) finger throughout the 25 minutes of each condition. The measurements of finger blood flow, expressed in absolute values (milliliters per $100 \mathrm{ml}$ per second) and as a percentage of the preexposure values, were averaged over the 5 minutes of each exposure period.

Brachial blood pressures were measured at the beginning and end of each experimental session. Room temperature was measured at 1-minute intervals. 

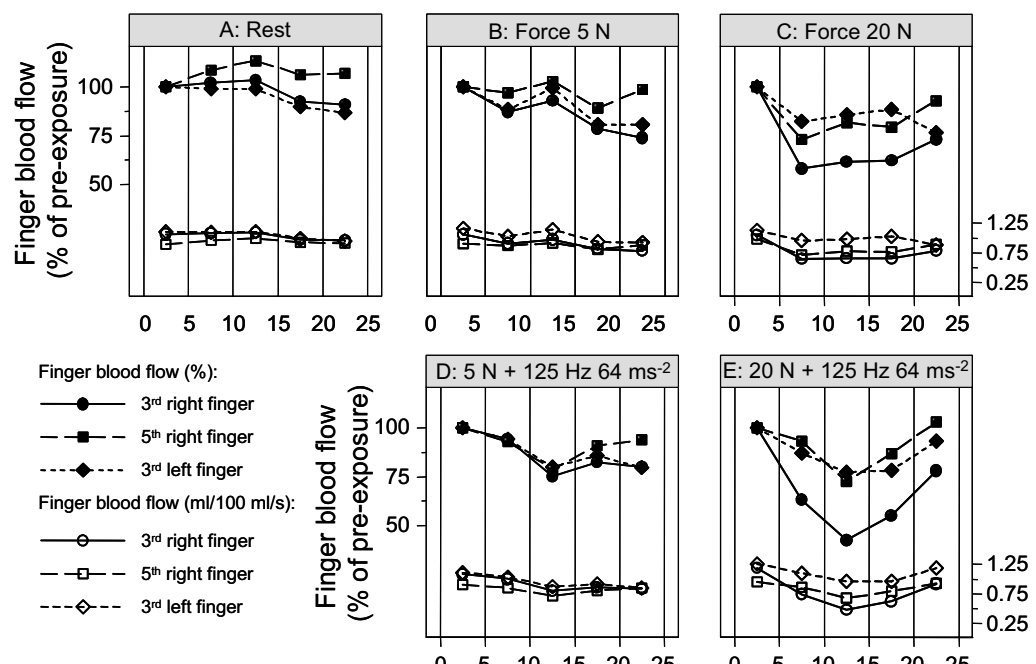

Figure 2. Finger blood flow (finger blood flow, milliliters per $100 \mathrm{ml}$ per second) and percentage change in the finger blood flow (\% of preexposure) in the middle right finger (exposed hand), the little right finger (exposed hand), and the middle left finger (unexposed hand) during the five exposure conditions (A to $E$ ) and the five exposure periods. (See Time (minutes) table 1.) The plotted symbols are mean values.

Table 2. Results of the repeated-measures analysis of variance.

\begin{tabular}{ll}
\hline Finger (between exposure conditions) & P-value \\
\hline Middle right finger & \\
Within period 2 (5 to 10 minutes) & $<0.001$ \\
Within period 3 (10 to 15 minutes) & $<0.001$ \\
Within period 4 (15 to 20 minutes) & $<0.01$ \\
Little right finger & \\
Within period 2 (5 to 10 minutes) & $<0.005$ \\
Within period 3 (10 to 15 minutes) & $<0.001$ \\
Middle left finger & \\
Within period 3 (10 to 15 minutes) & $<0.05$ \\
\hline
\end{tabular}

Each of the 10 participants experienced all five experimental conditions on 5 separate days. Across the participant group, the five experimental conditions were presented in a random order. The experimental sessions lasted approximately 45 minutes. All of the sessions were completed within a 3-week period.

The study was approved by the Human Experimentation Safety and Ethics Committee of the Institute of Sound and Vibration Research at the University of Southampton (UK).

\section{Statistical methods}

The data analysis was performed using the software package Stata (version 8.2 SE, Stata Corporation, College Station, TX, USA). The data were summarized with the mean as a measure of the central tendency and the standard deviation (SD) or the $95 \%$ confidence interval $(95 \% \mathrm{CI})$ as measures of dispersion.

The difference between paired means was tested by Student's t-test.

A repeated-measures analysis of variance (ANOVA) was used to test the hypothesis of no difference in the vascular responses under different exposure conditions. When the compound symmetry assumption (that is, that the measures have the same variance and the correlations between each pair of repeated measures are equal) was violated, a conservative test of the repeated-measures factor was used by reducing the degrees of freedom of the F-ratio (Greenhouse-Geisser method) (16). The 95\% Bonferroni confidence intervals for pairwise mean comparisons of the response were used when the probability value for the F-test of the repeated measures ANOVA was $\mathrm{P}<0.05$ (2-sided).

The relation between variables with repeated measures was assessed by the generalized estimating equations (GEE) method in order to account for the withinparticipant correlation (17).

\section{Results}

Figure 2 shows the overall pattern of the mean values of the finger blood flow (FBP) (expressed as milliliters per $100 \mathrm{ml}$ per second and as percentages of the preexposure values, ie, $\mathrm{FBP} \%$ ) in the middle and little right fingers (exposed hand) and in the middle left finger (unexposed hand) across the five exposure periods and the five exposure conditions. A repeated-measures ANOVA over the whole experiment revealed significant main effects for finger $(\mathrm{P}=0.003)$, exposure condition $(\mathrm{P}<0.001)$, and exposure period $(\mathrm{P}<0.001)$. Two-way (eg, period $\times$ condition) and three-way (finger $\times$ condition $\times$ period) interaction terms were also found to be significant $(\mathrm{P}<0.001)$ (table 2). As a result, data analysis was conducted separately within each finger and 
across the various exposure periods and exposure conditions.

\section{Finger circulation before exposure}

The vascular measurements during the first period, before exposure to either push force alone or push force and vibration (see table 1), showed no significant differences in finger blood flow in any finger of either the exposed or the unexposed hand across the five experimental sessions $(\mathrm{P}=0.47-0.83)$. During preexposure, the finger blood flow across the sessions averaged 1.09 $(95 \%$ CI $1.02-1.16) \mathrm{ml} /(100 \mathrm{ml} \cdot \mathrm{s})$ for the middle right finger, $0.92(95 \% \mathrm{CI} 0.86-0.98) \mathrm{ml} /(100 \mathrm{ml} \cdot \mathrm{s})$ for the little right finger, and 1.15 (95\% CI 1.07-1.23) $\mathrm{ml} /(100$ $\mathrm{ml} \cdot \mathrm{s})$ for the middle left finger. The preexposure measures of digital circulation showed that finger blood flow in the little right finger was significantly lower than that in the middle fingers of both hands $(\mathrm{P}<0.05)$.

Brachial systolic and diastolic arterial pressures measured before exposure did not change significantly for any of the participants across sessions (range of values across participants and sessions, 120/70-125/80 mm $\mathrm{Hg}$ ). No difference was observed for the brachial arterial blood pressures measured at the beginning and the end of the five sessions.

The volume of the fingers was not correlated with the baseline measures of digital circulation. For the middle finger of both hands $(\mathrm{P}<0.03)$, but not for the little right finger, finger blood flow was inversely related to the age of the participant.

For the preexposure period, the analysis of repeated measures by the GEE method showed no significant relation between finger blood flow and room temperature for any finger.

The repeated-measures ANOVA revealed no significant difference in the air temperature of the laboratory across the five experimental sessions $(\mathrm{P}=0.28)$ and the five exposure periods $(\mathrm{P}=0.20)$, ranges of the mean values being 25.4 (SD 0.7)-26.0 (SD 0.5) ${ }^{\circ} \mathrm{C}$.

\section{Circulatory effects of exposure to push force}

A repeated-measures ANOVA showed no significant difference in finger blood flow (expressed as either milliliters per $100 \mathrm{ml}$ per second or as the percentage of the preexposure level) for any finger over the first to fifth exposure periods during the resting condition (condition A) (figure 2).

There were no significant changes in the finger blood flow of any finger in either the exposed or the unexposed hand during the second period when compared with that of the preexposure, during exposure to solely a push force of $5 \mathrm{~N}$ (condition $\mathrm{B}$ ).

With $5 \mathrm{~N}$ applied to the palm of the right hand for 15 minutes (second to fourth periods) in condition B, the average finger blood flow in the right middle finger was reduced to $86.2 \%$ of that without force (during the preexposure period) in condition $\mathrm{B}(\mathrm{P}=0.04)$. The corresponding values for the other fingers were $96.4 \%$ for the little right finger $(\mathrm{P}=0.55)$ and $89.5 \%$ for the middle left finger $(\mathrm{P}=0.15)$. Exposure of the right hand to a push force of $20 \mathrm{~N}$ alone (condition $\mathrm{C}$ ) during the second period caused a significant reduction in finger blood flow in the middle and little right fingers $(\mathrm{P}<0.001)$ and the middle left finger $(\mathrm{P}<0.01)$ when compared with that of the preexposure period (figure 2).

With $20 \mathrm{~N}$ applied to the palm of the right hand for 15 minutes (second to fourth periods) in condition $\mathrm{C}$, the average finger blood flow in the right middle finger was reduced to $60.7 \%$ of that without force (during the preexposure period) in condition $\mathrm{C}(\mathrm{P}<0.001)$. The corresponding values for the other fingers were $78.0 \%$ for the little right finger $(\mathrm{P}<0.01)$ and $85.5 \%$ for the middle left finger $(\mathrm{P}=0.062)$.

When compared with the resting condition (condition A) during the second period, a push force of $20 \mathrm{~N}$ (condition C) provoked a significant decrease in the finger blood flow of the middle and little right fingers $(\mathrm{P}<0.01)$ (table 3). For the fingers of the right (exposed) hand, there was no significant difference in the change of the finger blood flow between the resting condition and a push force of $5 \mathrm{~N}$ during the second period, while $20 \mathrm{~N}$ was associated with a greater decrease in finger blood flow than with $5 \mathrm{~N}(\mathrm{P}<0.05)$ (figure 2).

Relative to blood flow without force during the second period in condition $\mathrm{A}$, there was a reduction in the finger blood flow of the middle left finger during exposure of the right hand to $5 \mathrm{~N}$ and $20 \mathrm{~N}(-7.7 \%$ and $-14.3 \%$ on the average, respectively), but the difference was not significant $(\mathrm{P}=0.21$ ) (table 3 ).

Table 3. Repeated-measures analysis of variance for testing the effects of push force on the percentage change in finger blood flow (\% of preexposure) in the second and fourth exposure periods (see table 1) -the mean square (MS) values and F-statistic and probability levels for the effect of push force was shown.

\begin{tabular}{|c|c|c|c|c|c|c|c|c|c|}
\hline \multirow[t]{2}{*}{ Exposure period } & \multicolumn{3}{|c|}{ Middle right finger (exposed hand) } & \multicolumn{3}{|c|}{ Little right finger (exposed hand) } & \multicolumn{3}{|c|}{ Middle left finger (unexposed hand) } \\
\hline & MS & $\mathrm{F}$ & P-value & MS & $\mathrm{F}$ & P-value & MS & $\mathrm{F}$ & P-value \\
\hline Period 2 & 3747 & 11.8 & $<0.001$ & 1654 & 4.77 & 0.003 & 423 & 1.54 & 0.21 \\
\hline Period 4 & 2337 & 4.09 & 0.008 & 963 & 1.69 & 0.17 & 243 & 0.46 & 0.76 \\
\hline
\end{tabular}




\section{Circulatory effects of combined exposure to push force and vibration}

A repeated-measures ANOVA revealed that combined exposure to push force and vibration during the third period induced significant changes in the finger blood flow of the monitored fingers of both the exposed and the unexposed hand (figure 2). For the middle right finger, a push force of $20 \mathrm{~N}$ combined with $125-\mathrm{Hz}$ vibration at $64 \mathrm{~m} / \mathrm{s}^{2} \mathrm{rms}$ (condition E) caused a significant decrease in finger blood flow when compared with that of any other experimental condition (A to D) $(0.001<\mathrm{P}<0.05)$. In the little right and middle left fingers, a push force of $20 \mathrm{~N}$ combined with vibration provoked a more pronounced decrease in the finger blood flow than in condition A (no force and no vibration) and condition $\mathrm{B}$ (push force of $5 \mathrm{~N}$ alone) $(0.001<\mathrm{P}<0.05)$.

Exposure to a push force of $5 \mathrm{~N}$ combined with vibration (condition D) was associated with a reduction of finger blood flow in each finger, which was significant only when compared with that of the resting condition with no force and no vibration (condition $\mathrm{A})(\mathrm{P}<0.05)$.

When the components of the exposure conditions (push force and vibration) were included separately in a repeated-measures ANOVA model, significant main effects of push force and vibration during the third pe- riod were observed for the fingers of the right (exposed) hand (table 4). A marginal effect of vibration was found for the middle finger of the left (unexposed) hand $(\mathrm{P}=0.07)$. There was no significant force-by-vibration interaction for any finger (figure 3) (ie, the effect of vibration was not significantly influenced by force and vice versa).

To estimate the contribution of vibration to the observed changes in finger blood flow, we calculated the difference between the percentage of change in the finger blood flow ( $\%$ of preexposure) in the third period and the percentage of change in the finger blood flow (\% of preexposure) in the second period to remove the effect of push force. After the contribution of force to the change in the finger blood flow was subtracted, the GEE method for repeated-measures analysis showed that exposure to $125-\mathrm{Hz}$ vibration with an unweighted acceleration magnitude of $64 \mathrm{~m} / \mathrm{s}^{2} \mathrm{rms}$ provoked a significant decrease in finger blood flow in all of the fingers of both the right (exposed) and the left (unexposed) hands (table 5). With condition A (no exposure to force and vibration) as the reference category, the reduction in the finger blood flow provoked by vibration exposure averaged $24.6 \%$ for the middle right finger $(\mathrm{P}<0.001), 24.7 \%$ for the little right finger $(\mathrm{P}<0.001)$, and $19.3 \%$ for the middle left finger $(\mathrm{P}<0.01)$.

Table 4. Repeated-measures analysis of variance for testing the effects of push force and vibration on the percentage change in finger blood flow (\% of preexposure) in the third exposure period (see table 1) -the mean square (MS) values and F-statistic and probability levels for the main effects of push force and vibration and for the force-by-vibration interaction term are shown.

\begin{tabular}{|c|c|c|c|c|c|c|c|c|c|}
\hline \multirow{2}{*}{$\begin{array}{l}\text { Source of } \\
\text { variation }\end{array}$} & \multicolumn{3}{|c|}{ Middle right finger (exposed hand) } & \multicolumn{3}{|c|}{ Little right finger (exposed hand) } & \multicolumn{3}{|c|}{ Middle left finger (unexposed hand) } \\
\hline & MS & $\mathrm{F}$ & P-value & MS & $\mathrm{F}$ & P-value & MS & $\mathrm{F}$ & P-value \\
\hline Force & 7364 & 24.7 & $<0.001$ & 2418 & 8.79 & 0.033 & 476 & 1.54 & 0.24 \\
\hline Vibration & 3428 & 6.52 & 0.03 & 2819 & 5.25 & 0.045 & 1968 & 4.11 & 0.07 \\
\hline Force $\times$ vibration & 4.81 & 0.02 & 0.90 & 568 & 0.74 & 0.41 & 305 & 0.84 & 0.38 \\
\hline
\end{tabular}

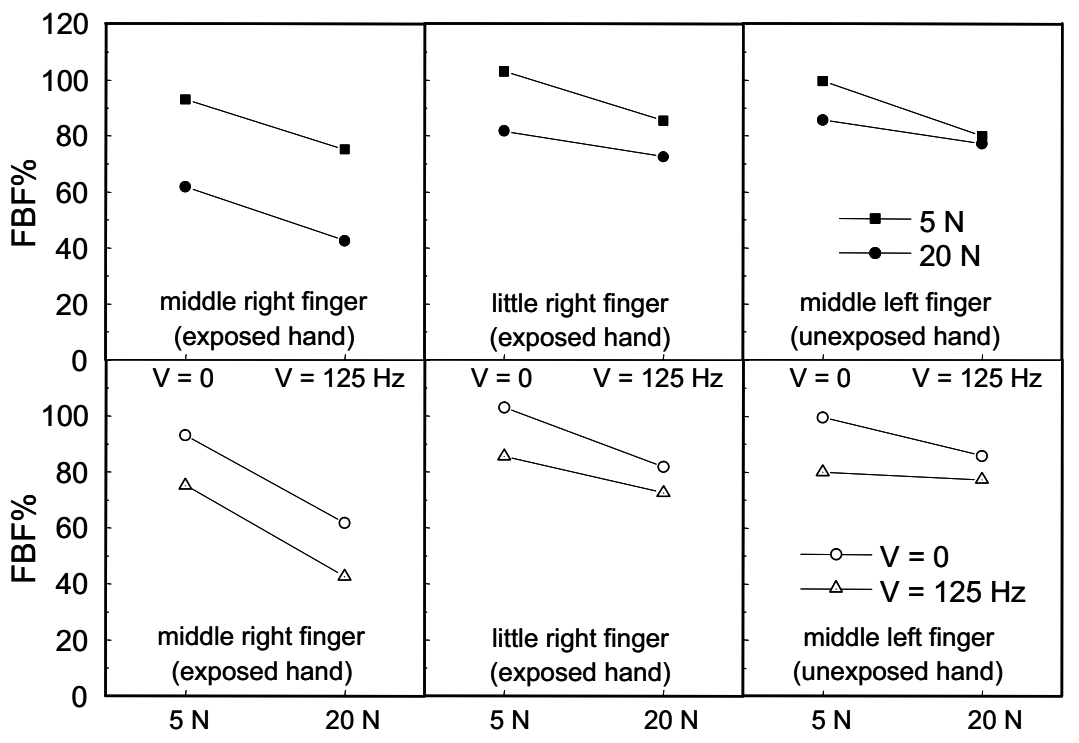

Figure 3. Effects of push force ( 5 or $20 \mathrm{~N}$ ) and vibration [0 (no vibration) or $125 \mathrm{~Hz}$ vibration] on the percentage change in finger blood flow (\% of preexposure) in the third exposure period. (See table 1.) 
Table 5. Regression of percentage change in finger blood flow (\% of preexposure) on exposure to push force and vibration (categorical predictors treated as dummy variables). The change in finger blood flow was calculated as the difference between the percentage of change in finger blood flow (\% of preexposure) in the third exposure period and the percentage change in finger blood flow (\% of preexposure) in the second exposure period. (See table 1.) Regression coefficients (robust $95 \%$ confidence interval) were estimated by the generalized estimating equation method for repeated-measures data on the assumption of no exposure to push force and no exposure to vibration as the reference category. The P-values were adjusted for multiple comparisons (Bonferroni method).

\begin{tabular}{|c|c|c|c|c|c|c|}
\hline \multirow[t]{2}{*}{ Predictors } & \multicolumn{6}{|c|}{ Change in finger blood flow (\%) } \\
\hline & $\begin{array}{l}\text { Middle right } \\
\text { finger (ex- } \\
\text { posed hand) }\end{array}$ & $95 \% \mathrm{Cl}$ & $\begin{array}{l}\text { Little right finger } \\
\text { (exposed } \\
\text { hand) }\end{array}$ & $95 \% \mathrm{Cl}$ & $\begin{array}{l}\text { Middle left finger } \\
\text { (unexposed } \\
\text { hand) }\end{array}$ & r $95 \% \mathrm{Cl}$ \\
\hline Intercept (no exposure) & 1.34 & $-9.28-11.9$ & 4.72 & $-3.47-12.9$ & -0.08 & $-8.48-8.32$ \\
\hline Force $5 \mathrm{~N}$ & 4.42 & $-11.6-20.5$ & 3.38 & $-10.2-17.0$ & 8.12 & $-11.8-28.0$ \\
\hline Force $20 \mathrm{~N}$ & 2.49 & $-11.6-16.6$ & 1.67 & $-12.3-15.7$ & 6.47 & $-8.17-21.1$ \\
\hline Vibration $125 \mathrm{~Hz}, 64 \mathrm{~m} / \mathrm{s}^{2}$ root mean square & -24.6 & $-42.1--7.19$ a & -24.7 & $-38.7--10.8^{a}$ & -19.3 & $-31.9--6.62^{b}$ \\
\hline
\end{tabular}

a $P<0.001$.

b $\mathrm{P}=0.003$.

A significant effect of push force on the change in finger blood flow during the fourth period (exposure to push force alone) was observed only in the middle finger of the right (exposed) hand (table 2). Consistent with the findings for the second period, $20 \mathrm{~N}$ during the fourth period induced a greater decrease in the finger blood flow of the middle right finger than either no force or $5-\mathrm{N}$ force $(\mathrm{P}<0.05)$. No significant effect of push force was observed for either the little finger of the right (exposed) hand or the middle finger of the left (unexposed) hand during exposure in the fourth period.

\section{Finger circulation after exposure}

There were no significant differences in the finger blood flow during the fifth period (ie, recovery) across the five experimental conditions for any of the three fingers $(\mathrm{P}=0.38-0.88)$. Compared with the preexposure, the finger blood flow in the fifth period was lower in the middle right finger in conditions $\mathrm{B}$ to $\mathrm{E}(\mathrm{P}<0.05)$ and in the middle left finger in condition $\mathrm{B}$ to $\mathrm{D}(\mathrm{P}<0.05)$, while no significant differences were found for the little right finger in any of the experimental conditions.

Compared with the average finger blood flow during the application of $20 \mathrm{~N}$ (during the second through the fourth periods) in condition $\mathrm{C}$, the subsequent percentage of finger blood flow during the recovery increased in the right middle finger (from $60.7 \%$ to $73.3 \%$, $\mathrm{P}=0.11$ ) and in the right little finger (from $78.0 \%$ to $93.0 \%, \mathrm{P}=0.44)$. However, for the left middle finger, the percentage of finger blood flow decreased from $85.5 \%$ to $76.5 \%(\mathrm{P}=0.12)$.

\section{Discussion}

The objectives of the study were to determine whether vibration applied to the palm of the hand reduced fin- ger blood flow and whether any reduction in blood flow caused by vibration was influenced by variations in the static force. The exposure conditions were chosen to be similar to those used in a previous study (13), and they were reasonably representative of the conditions causing vibration-induced white finger with regular prolonged exposures.

The marginal effect of $20-\mathrm{N}$ force applied by the right hand on finger blood flow in a finger on the left hand suggests a central sympathetic response. The 20$\mathrm{N}$ downward force by the hand required exertion of effort from the recumbent participants. It required more effort than the application of $5 \mathrm{~N}$ and appears to have provoked a generalized central vasoconstriction that was maintained during the 15 minutes of force.

In both fingers of the exposed hand, the vibration reduced finger blood flow similarly at both forces, with no interaction between the effects of vibration and force. There was also no significant interaction between the effects of vibration and force in the changes in finger blood flow in the third finger of the left (unexposed) hand, although the mean results suggest a greater effect of vibration with $5 \mathrm{~N}$ than with $20 \mathrm{~N}$. It appears that both vibration and force had an effect on finger blood flow in the contralateral hand but that the combination of high force and vibration had less effect than might have been expected from the separate effects of force and vibration, as seen in figure 3. In this contralateral hand, the effects of both force and vibration are assumed to arise from a central sympathetic response, which may have limited capability to cause vasoconstriction and might be limited to less vasoconstriction than seen in an exposed hand in which the vasoconstriction caused by force and vibration could arise from one or more local effects in addition to a central sympathetic effect.

For the exposed hand, the absence of a statistically significant interaction between force and vibration does not mean that the effects of force and vibration will always be additive. Possibly, force may cause greater 
changes in the transmission of vibration into the hand at some frequencies than at others, with an interaction at vibration frequencies not investigated in this study. Furthermore, other forces, or forces applied at other locations, may have different effects from those found in the current study.

With a 5-N force alone there was no significant vasoconstriction. The reduced finger blood flow with the combination of $5-\mathrm{N}$ force and $125-\mathrm{Hz}$ vibration was similar for all three fingers, this finding suggesting that the effects caused by this combination of vibration and force may have been predominantly influenced by a central sympathetic response.

During the 15-minute application of the $20-\mathrm{N}$ force alone in condition $\mathrm{C}$, the reduction in finger blood flow was significantly greater in the right middle finger than in both the right little finger $(\mathrm{P}=0.02)$ and the left middle finger $(\mathrm{P}<0.001)$, and there was no significant difference in the reduction of finger blood flow between the right little finger and the left middle finger $(\mathrm{P}=0.15)$. This finding may suggest that the increased force caused some compression of the vascular supply to the right middle finger but somewhat less compression of the vascular supply to the right little finger. With respect to the anatomy of the arterial tree in the palm of the hand, the wooden dome used in this study may have compressed the superficial palmar arterial arch and the common palmar digital arteries supplying the middle finger and the lateral side of the little finger, while less pressure was exerted on the palmar digital artery that supplies the medial side of the little finger.

With $20-\mathrm{N}$ force in combination with $125-\mathrm{Hz}$ vibration, the reduction in finger blood flow was significantly greater in the right middle finger than in the other two fingers. There was a similar pattern to the changes in finger blood flow in the exposed right little finger and the unexposed left middle finger, consistent with both being caused by a central sympathetic response. The greater reduction in finger blood flow in the right middle finger may be merely the addition of a central sympathetic effect to a local effect of tissue compression with this greater level of force.

The results of this study are broadly similar to those of our previous investigation with variations in vibration and force applied to the finger (13). In that study, increasing push forces $(0,2$ and $5 \mathrm{~N})$ were associated with increasing reductions of finger blood flow in the exposed finger, and these reductions were assumed to be due to local mechanical compression of the digital arteries. With force applied to the finger there was no significant change in finger blood flow in the unexposed ipsilateral and contralateral fingers, although the mean data may reflect some reductions. As in the present study, vibration caused reductions in finger blood flow in fingers not exposed to vibration.
Gripping a vibratory tool can require the application of forces that may reduce blood flow in tissues of the fingers either as a result of pressure on the arterial tree supplying these tissues or as a result of pressure applied directly to the local tissues of the fingers. There may also be a central response to the application of force, giving reduced blood flow at locations other than close to the location of application of force. Vibration-induced white finger develops in tissues to which vibration is applied, suggesting that local effects of vibration and pressure are involved, but the relative roles of vibration and pressure and any involvement of central responses are not yet understood.

The vibrations of tools cause oscillatory forces within tissues in addition to the static forces arising from pushing and gripping. Present and previous studies have shown that such fluctuating forces tend to reduce blood flow. However, the local effects of oscillatory forces will be frequency-dependent, and some may increase blood flow, such as seen with massage, for which the excitation is mainly at frequencies lower than studied in this investigation.

During the application of vibration and force, central and local effects such as those mentioned in this report may be expected to depend on the duration of application of the vibration and force. Furthermore, after the cessation of vibration and force, it cannot be assumed that the complex systems controlling blood flow will instantly return to their state before the application of vibration and force. As seen in this study and also previously (10-13), there can be after-effects as the vascular system recovers. Further study is needed to uncover the responsible mechanisms and understand their influences.

While the mechanisms responsible for the current findings are not well understood, there may be practical implications with regard to exposure to vibration from handheld power tools. It is clear that both vibration and force (or pressure) at the hands and fingers can reduce finger blood flow. Since one of the disorders caused by chronic exposure to hand-transmitted vibration is associated with reductions in finger circulation, it would be wise to minimize both force and vibration, as they can separately and collectively cause reductions in finger blood flow during acute exposure to vibration.

A $20-\mathrm{N}$ force applied to the palm of the hand can reduce blood flow in the fingers. Local reduction in finger blood flow in one or more fingers on the exposed hand may be explained by compression of the vascular system supplying the fingers. There is also evidence that force applied to the palm of one hand can reduce finger blood flow in the contralateral hand, possibly due to a central sympathetic effect. Vibration applied to the palm of a hand at a frequency of $125 \mathrm{~Hz}$ reduces finger blood flow in fingers on the exposed hand and also in fingers 
of the contralateral hand, the occurrence suggesting that the effect is primarily of central sympathetic origin.

\section{Acknowledgments}

This research was supported by the European Commission under the Promoting Competitive and Sustainable Growth Programme, project number G6RD-CT-200200843 (VIBTOOL).

\section{References}

1. Griffin MJ. Handbook of human vibration. London: Academic Press; 1990.

2. Griffin MJ. Measurement, evaluation, and assessment of occupational exposures to hand-transmitted vibration. Occup Environ Med. 1997;54:73-89.

3. European Committee for Standardization (CEN). Mechanical vibration-guide to the health effects of vibration on the human body. Brussels: CEN; 1996. CEN Report 12349.

4. Griffin MJ, Bovenzi M. The diagnosis of disorders caused by hand-transmitted vibration: Southampton Workshop 2000. Int Arch Occup Environ Health. 2002;75:1-5.

5. International Organization for Standardization (ISO). Mechanical vibration-measurement and evaluation of human exposure to hand-transmitted vibration, part 1: general requirements. Geneva: ISO; 2001. ISO 2001:5349-1.

6. The European Parliament, the Council of the European Union. On the minimum health and safety requirements regarding the exposure of workers to the risks arising from physical agents (vibration) [directive 2002/44/EC]. Off J Eur Commu- nities. 2002; 6th July:L177/13-19.

7. Griffin MJ. Minimum health and safety requirements for workers exposed to hand-transmitted vibration and wholebody vibration in the European Union; a review. Occup Environ Med. 2004;61:387-97.

8. Griffin MJ, Bovenzi M, Nelson CM. Dose-response patterns for vibration-induced white finger. Occup Environ Med. 2003;60:16-26.

9. Bovenzi M, Lindsell CJ, Griffin MJ. Response of finger circulation to energy equivalent combinations of magnitude and duration of vibration. Occup Environ Med. 2001;58:185-93.

10. Bovenzi M, Lindsell CJ, Griffin MJ. Duration of acute exposures to vibration and finger circulation. Scand J Work Environ Health. 1998;24(2):130-7.

11. Bovenzi M, Lindsell CJ, Griffin MJ. Magnitude of acute exposures to vibration and finger circulation. Scand J Work Environ Health. 1999;25(3):278-84.

12. Bovenzi M, Lindsell CJ, Griffin MJ. Acute vascular response to the frequency of vibration transmitted to the hand. Occup Environ Med. 2000;57:422-30.

13. Bovenzi M, Welsh AJL, Della Vedova A, Griffin MJ. Acute effects of force and vibration on finger blood flow. Occup Environ Med. 2005;63:84-91.

14. Welsh AJL, Griffin MJ The effect of vibration magnitude and push force on finger blood flow. Proceedings of the 10th International Conference on hand-arm vibration, Las Vegas, 7-11 June 2004. pp 167-8.

15. Greenfield ADM, Whitney RJ, Mowbray JF. Methods for the investigation of peripheral blood flow. $\mathrm{Br}$ Med Bull. 1963;19:101-9.

16. Greenhouse SW, Geisser S. On methods in the analysis of profile data. Psychometrika. 1959;24:95-111.

17. Diggle PJ, Liang KY, Zeger SL. Analysis of longitudinal data. Oxford (UK): Oxford University Press; 1994. Oxford Statistical Science Series, no 13.

Received for publication: 31 January 2006 